ISSN: 0213-2060

DOI: http://dx.doi.org/10.14201/shhme201634297320

\title{
CONFLICTOS VIOLENTOS EN EL SENO DE LAS OLIGARQUÍAS DE LAS CIUDADES CASTELLANAS A FINES DE LA EDAD MEDIA: LOS «BANDOS» DE ÁVILA
}

\author{
Violent Conflicts within the Oligarchical Groups of the Castilian Towns \\ at the End of the Middle Ages: the "Bandos» of Avila
}

\author{
Máximo DIAGO HERNANDO \\ Instituto de Historia. Consejo Superior de Investigaciones Cientificas. C/ Albasanz, 26-28. E-28037 MADRID. \\ C.e.: maximo.diago@cchs.csic.es
}

Recibido: 2015-05-11

Revisado: 2015-07-13

Aceptado: 2016-10-14

RESUMEN: El autor analiza las luchas banderizas entre las dos principales casas nobles de la ciudad de Ávila a fines del siglo xv y comienzos del siglo xvi. Trata de determinar si hubo conexiones entre estas luchas y la pertenencia de las familias que constituían el grupo oligárquico abulense a dos instituciones llamadas los linajes de San Vicente y San Juan, que servían para garantizar el pacífico reparto de los oficios de gobierno local. Y llega a la conclusión de que en la época analizada dichos linajes ya no constituían auténticas facciones, estructuradas de forma jerárquica, porque en su seno se habían desarrollado divisiones entre grupos de regidores que se disputaban entre sí el poder.

Palabras clave: Castilla; Nobleza urbana; Luchas de bandos; Conflictos políticos urbanos; Siglo Xv; Siglo XVI.

ABSTRACT: The author analyzes the factional strifes between the two most prominent noble houses of the city of Ávila that took place at the end of the fifteenth and at the beginning of the sixteenth century. He tries to verify if there was any kind of connexion 


\section{MÁXIMO DIAGO HERNANDO \\ CONFLICTOS VIOLENTOS EN EL SENO DE LAS OLIGARQUÍAS DE LAS CIUDADES CASTELLANAS \\ A FINES DE LA EDAD MEDIA: LOS «BANDOS» DE ÁVILA}

between these strifes and the affiliation of the families of the local oligarchy of the city to two local institutions that were called the linajes (lineages) of Saint Vicent and Saint John that guaranteed the peaceful distribution of the offices of local government in the city. He arrives to the conclusion that at the analyzed period these linajes were not genuine factions with a hierarchical structure, because divisions between groups of aldermen that rivalled for power had developed within them.

Keywords: Castile; Urban nobility; Urban political conflicts; Factional strifes; Fifteenth Century; Sixteenth Century.

SUMARIO: 0 Introducción. 1 Linajes y bandos en Ávila hasta la muerte de Isabel la Católica. 2 Luchas de bandos tras la muerte de Isabel la Católica. 3 Conflictos en el seno de los bandos-linaje por la provisión de oficios. 4 Conclusión. 5 Referencias bibliográficas.

\section{INTRODUCCIÓN}

Los conflictos políticos proliferaron en las ciudades castellanas durante el período bajomedieval, pero, a diferencia de lo que ocurrió en otros ámbitos de Europa, una parte muy importante de los que se plantearon, y que mayor grado de persistencia mostraron, fueron los surgidos en el seno del propio grupo dominante como consecuencia del desarrollo de rivalidades entre facciones por la consecuención de la hegemonía en el ámbito local.

Ciertamente algunas corrientes historiográficas han tendido a minusvalorar la importancia que estos conflictos entre facciones en el seno de los grupos caballerescos que gobernaban las ciudades castellanas alcanzaron durante el período bajomedieval, orientando por el contrario sus esfuerzos a poner de manifiesto el alto grado de «cohesividad» alcanzado por los grupos dominantes en los sistemas políticos urbanos, que se habría traducido en un sostenido afán por buscar la resolución de los conflictos mediante la negociación, con un sosfisticado despliegue de recursos discursivos, en lugar de mediante el recurso a la violencia ${ }^{1}$.

Por supuesto, este afán por resaltar la importancia que la búsqueda del «consenso» tuvo en el universo político de la Castilla bajomedieval, que tan extendido se encuentra entre los medievalistas del momento presente, no ha impedido tomar conciencia de la difusión que alcanzaron entonces las acciones violentas en la vida política, pues las fuentes están plagadas de noticias que lo confirman. Así, entre los autores que más atención han dedicado a poner de manifiesto la importancia que el recurso a la violencia tuvo como instrumento de acción política en las ciudades castellanas bajomedievales destaca Monsalvo Antón. En sus numerosos estudios este autor llega a definir el ejercicio de la violencia como elemento fundamental de la «cultura política» de los miembros del grupo

1 Jara Fuente, José Antonio. Concejo, poder y élites. La clase dominante de Cuenca en el siglo XV. Madrid: Consejo Superior de Investigaciones Científicas, 2000. 
MÁXIMO DIAGO HERNANDO

CONFLICTOS VIOLENTOS EN EL SENO DE LAS OLIGARQUÍAS DE LAS CIUDADES CASTELLANAS A FINES DE LA EDAD MEDIA: LOS «BANDOS» DE ÁVILA

privilegiado caballeresco, en contraposición a los del Común de pecheros, más inclinados a la defensa de sus derechos e intereses mediante el recurso a la ley y a las instituciones². Según él, sin embargo, los usos violentos definen la acción política de los caballeros en las grandes ciudades de la Meseta, ante todo en su relación con los dominados, es decir, pecheros urbanos y campesinos. Y por ello tiende a infravalorar el potencial desestabilizador de las relaciones políticas en los ámbitos urbanos que tuvo el recurso a la violencia de los caballeros contra los propios caballeros en las luchas de bandos, incluso en los casos en que las mismas alcanzaron notable grado de desarrollo, como ocurrió en Ciudad Rodrigo o Salamanca, por entender que se trató de conflictos que se generaron preferentemente como consecuencia de las interferencias de influencias externas, de origen «extraconcejil», o fueron el resultado de simples querellas particulares entre individuos o familias, sin connotaciones políticas evidentes ${ }^{3}$.

Sin duda, al abordar esta cuestión, las generalizaciones son peligrosas, porque las distintas ciudades presentaron fuertes singularidades en sus estructuras sociopolíticas y organización institucional, aunque todas compartiesen un mismo modelo básico. Por ello resulta necesario avanzar en la realización de trabajos centrados en el análisis de las distintas ciudades en particular, para, a partir de sus resultados, poder acometer con mayores garantías análisis comparativos que permitan sustentar sobre bases más firmes los modelos explicativos con pretensiones generalizadoras. En consecuencia, partiendo de estos presupuestos, nos hemos propuesto en el presente artículo profundizar en el estudio del caso singular de la ciudad de Ávila, desde la perspectiva del papel que en su vida política desempeñaron los bandos-linaje y las luchas de facciones.

A diferencia de Salamanca, donde los bandos han quedado muy grabados en la memoria colectiva, en la ciudad del Adaja no se los recuerda tanto como un elemento fundamental de su pasado medieval. Pero también allí alcanzaron notoria relevancia, pues no en vano era una ciudad muy marcada en sus estructuras sociopolíticas por la presencia de un nutrido grupo de caballeros con una marcada inclinación a defender sus intereses y resolver sus diferencias mediante el recurso a la violencia. Hasta tal punto fue así que llegó a ser conocida con el sobrenombre de "Ávila de los caballeros», caracterizándose su paisaje urbano por la proliferación de edificios fortificados que suponían una grave amenaza para el orden público, por lo que la Monarquía se esforzó por poner freno a su construcción ${ }^{4}$.

2 Monsalvo Antón, José M.a. «Torres, tierras, linajes: Mentalidad social de los caballeros urbanos y de la elite dirigentes en la Salamanca medieval (Siglos XiII-Xv)». En Monsalvo Antón, José M. a. (ed.). Sociedades urbanas y culturas politicas en la baja Edad Media castellana. Salamanca: Ediciones Universidad de Salamanca, 2013, pp. 165-230. Sobre el ideario político de los pecheros, ÍDEM. «Ideario sociopolítico y valores estamentales de los pecheros abulenses y salmantinos (ss. XIII-Xv)». Hispania, vol. 238, 2011, pp. 325-362.

3 Vid. Monsalvo Antón, José M.a. «Las luchas de bandos en Ciudad Rodrigo durante la época Trastámara». En Val Valdivieso, M. ${ }^{a}$ Isabel del y Martínez Sopena, Pascual (dirs.). Castilla y el mundo feudal. Homenaje al profesor Julio Valdeón. Valladolid: Junta de Castilla y León-Universidad de Valladolid, 2009, vol. III, pp. 201-214. ÍDEM. «Violence between factions in medieval Salamanca. Some problems of interpretation». Imago Temporis. Medium Aevum, 2009, vol. 3, pp. 139-170.

4 En 1514 se denunció a Gómez de Ávila por haber comenzado a edificar una torre cerca de la catedral: AGS (= Archivo General de Simancas), RGS (= Registro General del Sello), VII-1514. 
MÁXIMO DIAGO HERNANDO

300

CONFLICTOS VIOLENTOS EN EL SENO DE LAS OLIGARQUÍAS DE LAS CIUDADES CASTELLANAS

A FINES DE LA EDAD MEDIA: LOS «BANDOS» DE ÁVILA

La importancia de las luchas de bandos en la trayectoria medieval de Ávila ha sido reconocida por la historiografía local, aunque sin profundizar en su análisis y caracterización, por lo que la información aportada en torno a ellas es parcial y a veces incluso contradictoria. Por ejemplo, llama la atención que la norteamericana Bilinkoff, remitiéndose a eruditos abulenses, sostenga que los enfrentamientos violentos entre los bandos persistieron en Ávila hasta 1504, pasando por alto el hecho de que tras esta fecha tuvo lugar uno de los más graves de los que ha quedado constancia documental en toda la historia de la ciudad5.

Desde el punto de vista de la historia comparada de las ciudades castellanas, el análisis de los bandos de Ávila presenta un indiscutible interés porque en esta ciudad existió la institución del «bando-linaje», como estructura destinada a facilitar el reparto ordenado de las parcelas de poder local entre las principales familias que conformaban el grupo oligárquico, a diferencia de lo que ocurrió en la mayoría de las de la mitad meridional del reino que conocieron cruentas luchas de facciones durante el siglo xv y las primeras décadas del siglo Xvi, como es el caso de Córdoba, Sevilla, Úbeda, Baeza, Toledo o Cuenca, donde entonces no se conoció tal institución. Por supuesto, el caso de Ávila no fue único desde este punto de vista, ya que también en otras muchas ciudades de la Meseta, como Salamanca o Ciudad Rodrigo, constatamos una situación semejante. Pero, como consecuencia de la posición singular que en la estructura sociopolítica abulense ocuparon las casas de Villatoro-Navamorcuende y Villafranca-Las Navas, los bandos de Ávila presentan ciertas peculiaridades que merece la pena valorar.

Para clarificar estas cuestiones y profundizar en la caracterización de la compleja realidad que constituyeron los enfrentamientos banderizos en las ciudades castellanas tardomedievales, acometemos, pues, el presente trabajo dedicado al caso abulense. Con él pretendemos avanzar en el conocimiento de lo que realmente fueron los bandos-linaje, y al mismo tiempo someter a comprobación las tesis de aquellos autores para los que la búsqueda del consenso prevaleció en la vida política de las ciudades castellanas medievales sobre el recurso a la violencia contra los oponentes.

\section{Linajes y bandos en Ávila hasta la muerte de Isabel la Católica}

Tomaremos como punto de arranque para el estudio de los conflictos banderizos en Ávila los ańos de la minoría de Alfonso XI, periodo de notoria inestabilidad política, durante el que proliferaron en esta ciudad los desórdenes en los que se abusó del recurso a la violencia. Por el ordenamiento dado a la ciudad por este monarca en 1330 nos consta que se había visto afectada por la existencia de bandos que habían generado frecuentes disturbios, como consecuencia de los comportamientos violentos y prepotentes de que habían hecho gala los caballeros ${ }^{6}$. El ordenamiento trató de poner fin a esta situación, para pacificar la ciudad, pero desconocemos en qué medida lo logró.

5 Bilinkoff, Jodi. The Avila of St. Teresa. Religious Reform and Urban Development, 1480-1620. Ann Arbor: University Microfilms International, 1983, p. 47.

6 Moreno Núñez, José Ignacio. Ávila y su Tierra en la Baja Edad Media (Siglos XIII-XV). Valladolid: Junta de Castilla y León, 1992, pp. 150-153. 
MÁXIMO DIAGO HERNANDO

CONFLICTOS VIOLENTOS EN EL SENO DE LAS OLIGARQUÍAS DE LAS CIUDADES CASTELLANAS A FINES DE LA EDAD MEDIA: LOS «BANDOS» DE ÁVILA

Lo que sí podemos constatar es que con posterioridad los miembros del estamento privilegiado caballeresco terminaron quedando allí repartidos entre dos bandos-linaje, los de San Vicente y de San Juan, que funcionaban como instituciones que aseguraban la equitativa distribución de oficios, prebendas, honores y todo tipo de parcelas de poder entre las principales familias de caballeros que conformaban dicho estamento. Así lo atestigua un documento del año 1396 relativo a la concesión de una dehesa a una aldea ${ }^{7}$. Reconstruir el proceso de aparición y consolidación de dichos linajes es tarea complejísima, por falta de fuentes documentales. Y por ello resulta de momento imposible llegar a conclusiones seguras sobre si su cristalización como instituciones al servicio del reparto ordenado del poder local fue resultado de algún acuerdo de pacificación que pusiese fin a un período previo, más o menos prolongado, de enfrentamientos banderizos violentos.

En el estado actual de la investigación, uno de los aspectos que de forma más clara percibimos del perfil de estos dos linajes es que, aunque llegaron a agrupar un gran número de familias de caballeros de muy diverso origen, a la cabeza de cada uno de ellos consiguieron colocarse en posición preeminente dos casas que mantuvieron una relación de mutua hostilidad a lo largo de varias generaciones: la de los señores de Villatoro y Navamorcuende, en el linaje de San Vicente, y la de los de Villafranca y Las Navas, en el de San Juan.

Dejando a un lado la primera mitad del siglo xv, para la que no hemos recopilado aún suficiente información, nos encontramos que en los tumultuosos años del final del reinado de Enrique IV Ávila fue escenario de frecuentes desórdenes resultado de los enfrentamientos banderizos. Lo demuestran las drásticas medidas aprobadas el 8 de julio de 1469 por la princesa Isabel para pacificar y restablecer el orden en la ciudad. Obligó entonces a los caballeros y escuderos de ambos linajes a jurar y firmar una serie de capítulos, decretando «seguro de bando a bando", con penas severas para quienes quebrantasen la tregua. Y para el caso de que se produjese algún desorden (ruido) obligaba a Pedro de Ávila, señor de Las Navas, a avisar a Gonzalo de Ávila, señor de Villatoro, para que se responsabilizasen ambos de que todos permanecían dentro de sus casas hasta que el orden hubiese sido restablecido ${ }^{8}$. Se les reconocía así a ambos un papel dirigente al frente de cada una de las facciones. Y, en efecto, los dos eran en aquellos momentos individuos de notorio relieve político, que habían tejido una tupida red de alianzas con otros destacados miembros de la sociedad política regional. Así, cabe recordar, por ejemplo, que en 1461 Gonzalo Dávila, junto con Alonso de Fonseca, señor de Coca y Alaejos, y Âlvaro de Bracamonte, señor de Peñaranda, habían firmado una confederación con dos regidores de la ciudad de Segovia, que representaban a todos los caballeros y escuderos «de la parentela de San Millán de los Caballeros», por virtud de la cual acordaban prestarse mutuamente ayuda militar cuando la necesitasen?

7 Monsalvo Antón, José M.a. «El realengo y sus estructuras de poder durante la Baja Edad Media». En Ser Quijano, Gregorio del (coord.). Historia de Avila. III. Edad Media (Siglos XIV-XV). Ávila: Institución Gran Duque de Alba, 2006, pp. 71-176, en particular pp. 124 y ss.

8 Moreno Núñez, Avila y su Tierra, p. 157. Monsalvo Antón, «El realengo», p. 128.

$9 \quad \operatorname{AHN}(=$ Archivo Histórico Nacional), Nobleza (Toledo), Frías, 14-17. 
MÁXIMO DIAGO HERNANDO

302

CONFLICTOS VIOLENTOS EN EL SENO DE LAS OLIGARQUÍAS DE LAS CIUDADES CASTELLANAS

A FINES DE LA EDAD MEDIA: LOS «BANDOS» DE ÁVILA

Es probable que las medidas dictadas en 1469 por la princesa Isabel para la pacificación de los bandos tropezasen con numerosos obstáculos para cumplirse, habida cuenta que la inestabilidad que reinaba en el conjunto del reino no generaba el clima propicio para ello. De hecho, aunque las referencias encontradas en la documentación son parcas, hay algunas que sugieren que la rivalidad entre los bandos encabezados por las casas de Villatoro y Villafranca continuó provocando alteraciones del orden público en la ciudad del Adaja. En concreto Monsalvo Antón alude a unos nuevos capítulos de tregua que fueron pregonados y jurados ante el sepulcro de San Vicente en julio de $1476^{10}$. Y tanto este autor como Moreno Núnez aluden a medidas tomadas por los Reyes Católicos en 1477 para castigar a los que habían tomado parte en unos disturbios ocurridos entre el señor de Villatoro y otros oponentes no identificados, de los que habían resultado muertes ${ }^{11}$.

El fortalecimiento de las instituciones de gobierno de la Monarquía tras las Cortes de Toledo de 1480 propiciaría que el desbordamiento violento de las rivalidades banderizas se fuese haciendo cada vez más raro. Pero las tensiones entre los bandos y las dos casas que los encabezaban no se relajaron en absoluto, persistiendo la amenaza de que saliesen de nuevo a la superficie para provocar graves desórdenes. Buena prueba de ello es que varias veces los monarcas tuvieron que ordenar el destierro de algunos caballeros principales, por haber dado lugar a alborotos que habían supuesto una grave alteración del orden público. Así, en julio de 1492 ordenaron al corregidor de Ávila que desterrase de la ciudad al señor de Villatoro, Fernán Gómez Dávila, por un período de seis meses, por haber sido encontrado culpable por el pesquisidor Bernardo de Pisa de haber provocado, junto a otros caballeros, cierto «ruido y escándalo», que había estado a punto de causar incluso muertes, por un asunto relacionado con el matrimonio de una hija de Nuño Rengifo ${ }^{12}$.

Estos disturbios de 1492 no parece que estuviesen relacionados con las viejas rencillas con la casa de Villafranca, pero otros documentos nos confirman que la visceral animadversión entre ambas no había cedido un ápice. En concreto, una real provisión de diciembre de 1496 recoge la denuncia presentada en el Consejo Real por Fernán Gómez Dávila, por razón de la compra que acababa de realizar Pedro Dávila de una sinoga (sinagoga), que se ubicaba enfrente de su casa, y de unas casas que habían pertenecido a Alvar Gómez, las cuales se localizaban a la salida de sus casas a la calle. Según él, de estas compras se le seguía un gran perjuicio, porque Pedro de Ávila no las había realizado "con buen propósito" y, teniendo en cuenta la localización de las casas en cuestión, de su posesión por parte de este caballero «resultaba discordia» ${ }^{13}$. En circunstancias normales no tendría por qué haber sido así, pero el señor de Villatoro estaba aludiendo a la arraigada enemistad que el de Villafranca le profesaba, que ya en más de una ocasión habría dado lugar a reyertas violentas en el pasado, más difíciles de controlar si ambos vivían en casas contiguas.

Que esta enemistad se agravó en los años siguientes nos es confirmado por el hecho de que la propia Reina Católica, en sus últimos meses de vida, tuvo que intervenir para

10 Monsalvo Antón, «El realengo», p. 130.

11 Moreno Núñez, Ávila, pp. 157-158; y Monsalvo Antón, «El realengo», p. 130.

12 AGS, RGS, VII-1492, fol. 106.

13 AGS, RGS, XII-1496, fol. 137. 
impedir que diese lugar de nuevo al estallido de la violencia. Fue en marzo de 1504, cuando un alcalde de Casa y Corte, el licenciado Sancho Sánchez de Montiel, fue comisionado para que derramase las gentes de armas que en Ávila habían reunido de una parte Pedro de Ávila y sus hijos, y de otra Fernán Gómez de Ávila, con las cuales estaban protagonizando algunas peligrosas «asonadas» ${ }^{14}$. No hemos podido determinar el motivo concreto por el que habían iniciado tal reclutamiento de tropas, que una vez más venía a poner de relieve la fragilidad de la pacificación de los bandos conseguida por los Reyes Católicos. Sí nos interesa resaltar, no obstante, que la Monarquía en esta ocasión actuó con contundencia para cortar de raíz cualquier desafío a su autoridad. Lo deducimos de la noticia de que el mencionado alcalde de Casa y Corte terminó desplazándose a la villa de Navamorcuende a tomar posesión de ella en nombre de los reyes, y procedió a embargar las rentas que Fernán Gómez de Ávila percibía en ella ${ }^{15}$. Tras la muerte de la reina, en noviembre de 1504 , la situación política del reino experimentaría un repentino vuelco, y este cambio también se dejó percibir en la evolución de las tensiones banderizas en Ávila, que adoptaron, como comprobaremos a continuación, un cariz mucho más violento, ante la impotencia de las instituciones de gobierno de la Monarquía.

\section{Luchas de bandos tras la muerte de Isabel la Católica}

Tras la muerte de la reina el repentino debilitamiento experimentado por las instituciones de gobierno de la Monarquía como consecuencia de las disputas sucesorias propició que en muchas de las grandes ciudades del reino, donde sus grupos oligárquicos nobles se encontraban fracturados en irreconciliables facciones, resurgiesen con pleno vigor los enfrentamientos violentos entre estas. Hay testimonios del resurgir de las luchas de bandos a partir de 1505, y de forma muy especial en el transcurso del año 1506, en numerosas grandes ciudades de la Meseta y Andalucía, de entre las que cabría destacar las de Sevilla, Übeda, Baeza, Toledo y Cuenca ${ }^{16}$.

Ávila se cuenta entre estas ciudades, y destaca incluso por la gravedad de los desórdenes que allí se desencadenaron a partir de 1505, y con mayor virulencia en los meses posteriores a la muerte del rey Felipe, que conllevaron reiteradas acciones de obstinado desacato a las instituciones de gobierno de la Monarquía. La desaparición de la reina fue

14 AGS, RGS, IV-1504.

15 AGS, RGS, X-1505, fol. 214

16 Sobre Sevilla, vid. Ladero Quesada, Miguel Ángel. Guzmán. La casa ducal de Medina Sidonia en Sevilla y su reino. 1282-1521. Madrid: Dykinson, 2015, pp. 309-337. Sobre Úbeda y Baeza, vid. RoDríguez Molina, José. «Bandos en las ciudades del Alto Guadalquivir (Siglos XV-Xvi). Repercusiones». En Las ciudades andaluzas (siglos XIII-XVI). Actas del VI Coloquio Internacional de Historia Medieval de Andalucía. Málaga: Universidad de Málaga, 1991, pp. 37-50. También interesa, AGS, Cámara-Personas, leg. 18, y Cámara-Memoriales, leg. 116, fol. 109. Sobre Toledo, vid. López Gómez, Óscar. La sociedad amenazada. Crimen, delincuencia y poder en Toledo a finales del siglo XV. Toledo: Ayuntamiento de Toledo, 2007, pp. 284 y ss. Sobre Cuenca, vid. Diago Hernando, Máximo. «La alta nobleza en la vida política de las ciudades castellanas en las décadas precomuneras: el ejemplo de Cuenca (1506-1507)». Cuadernos de Historia Moderna, 1994, vol. 15, pp. 121-141. 
MÁXIMO DIAGO HERNANDO

304

CONFLICTOS VIOLENTOS EN EL SENO DE LAS OLIGARQUÍAS DE LAS CIUDADES CASTELLANAS

A FINES DE LA EDAD MEDIA: LOS «BANDOS» DE ÁVILA

aprovechada por los más belicosos miembros del estamento caballeresco para dar rienda suelta a sus ambiciones, lanzándose a la comisión de todo tipo de desmanes, sin que les frenase el temor a un inminente castigo regio.

En Ávila, entre 1505 y 1508, se superpusieron varios conflictos entre miembros del estamento privilegiado de los caballeros, que obedecían a motivaciones concretas diferentes. Así, por ejemplo, tenemos que en el seno de la familia de los Dávila, señores de San Román, había planteado desde hacía tiempo un pleito entre el primogénito y sus hermanos sobre la asignación de determinadas heredades al mayorazgo, que se reactivó en el año 1505, cuando una de las partes en litigio, la de los hermanos excluidos del mayorazgo, se quejó de las dificultades con que tropezaba para que se le hiciese justicia como consecuencia de la amistad que la parte contraria tenía con el seńor de Villatoro, quien disfrutaba de notable capacidad de influencia sobre los oficiales de la justicia ${ }^{17}$.

Por otro lado, nos consta que en septiembre de este mismo año actuaba en la ciudad como juez pesquisidor el doctor Avellán, comisionado para averiguar y castigar a los culpables de haber participado en unos enfrentamientos acaecidos entre los Bullones y Juan de Bracamonte. En ejercicio de sus funciones este juez decidió tomar preso a un hijo del deán, para lo cual solicitó al corregidor que le proporcionase favor y ayuda. Pero, cuando se acercaron a la casa donde este se encontraba, alrededor de veinte hombres armados salieron a la puerta y se resistieron violentamete a los oficiales de la justicia, en un acto de grave desacato, para marchar a continuación a la iglesia de San Vicente, donde atacaron con lanzas a un hombre del alcaide. Y poco después allí acudieron a reforzarles otros cincuenta hombres «armados y empavesados», la mayoría con arneses, que habían sido enviados por doña Elvira de Zúñiga, viuda de Esteban Dávila. Para castigar a los culpables de esta acción de resistencia armada a los oficiales de la justicia, que había motivos para sospechar que había sido planificada, fue comisionado en septiembre de 1505 un alcalde de Corte, el licenciado Gallego ${ }^{18}$.

Esta es la primera ocasión en que nos encontramos involucrada en violentos desórdenes a esta dama, hermana del duque de Béjar. Pero a partir de entonces las noticias se multiplican, pues ella fue la que junto con su hijo Pedro Dávila, señor de Las Navas y Villafranca, y su cuñado el regidor Fernán Álvarez de Toledo, estuvo al frente de uno de los dos bandos que con sus disputas más contribuyeron a sembrar la violencia en la ciudad del Adaja en los años 1506 y 1507. Se trataba del bando que en vida de Isabel la Católica había liderado el poderoso caballero Pedro Dávila, quien había muerto hacia 1504, dejando sus señoríos a su hijo Esteban Dávila, que le siguió a la tumba poco después, por lo que correspondió a su viuda, hacerse cargo de la defensa de los intereses de su hijo Pedro, con la colaboración del hermano menor de su difunto marido, el regidor Fernán Álvarez de Toledo. Precisamente este había sido designado por la ciudad de Ávila como procurador para las Cortes convocadas en 1505 para jurar a la nueva reina, dońa Juana. Y, habiéndose trasladado al lugar donde se celebraría la asamblea, la ciudad de

17 Tapia Sánchez, Serafín de. "Ávila en la encrucijada de Castilla: La rebelión de las Comunidades». En Martín García, Gonzalo (coord.) Historia de Ávila. V. Edad Moderna (Siglos XVI-XVIII. 1. a Parte). Ávila: Institución Gran Duque de Alba, 2013, pp. 145-235, en particular p. 155.

18 AGS, RGS, IX-1505. 
Toro, recibió al poco licencia del rey para ausentarse y poder regresar a Ávila, «a ciertas cuestiones que mucho le iban», dejando en su lugar para que le sustituyese en las funciones de procurador al regidor Cristóbal Blázquez" ${ }^{19}$. Sin duda las mencionadas "cuestiones» no eran otras que las diferencias que su casa mantenía con la casa de Villatoro, las cuales, como hemos visto, ya a comienzos de 1504 habían dado lugar a ayuntamientos de tropas por parte de su padre, Pedro de Ávila, y de su rival, Fernán Gómez de Ávila.

Tras la muerte de Isabel la Católica, el choque entre las casas de Villatoro y Villafranca, que ya con evidente dificultad la difunta reina se había esforzado por evitar en sus últimos meses de vida, no tardó, en efecto, en producirse. Y lo hizo con importantes dosis de violencia y notorio despliegue de actitudes de desacato hacia la autoridad monárquica. Fue, sin duda, el conflicto que más contribuyó a desestabilizar la vida política de Ávila en estos críticos ańos. Y por ello interesa que nos detengamos en su análisis, aunque sin dar cuenta pormenorizada de los acontecimientos en que se tradujo, pues ya se dispone de trabajos en que se ha llevado a cabo dicha tarea de forma satisfactoria ${ }^{20}$.

Como hemos señalado, existían precedentes que no dejaban lugar a dudas sobre el potencial desestabilizador que encerraba la visceral enemistad existente entre estas dos casas. Por ello, ante la aparición de las primeras señales de alarma, las instituciones de gobierno de la Monarquía decidieron intervenir. Y, conscientes del peligro que representaba la permanencia en la ciudad de Ávila de los dirigentes de ambas facciones, que fácilmente podían transformar sus casas principales en auténticas fortificaciones desde las que sembrar la violencia en todo el recinto urbano, conminaron a estos a que la abandonasen y se retirasen a residir a un lugar de su señorío, imponiéndoles además la observancia de una tregua ${ }^{21}$. Además, para impedir la conversión de dichas casas principales en nidos de violencia, que pudiesen escapar al control de la autoridad, decidieron realizar drásticas intervenciones arquitectónicas en las mismas, que contribuyesen a atenuar su peligrosidad. En concreto sabemos que las casas principales de los dos mayorazgos que se disputaban la hegemonía en Ávila estaban pegadas a la muralla y que, para facilitar el acceso a las mismas de sus propietarios y de los miembros de sus clientelas, en ambas se habían abierto sendos postigos en el tramo de la muralla en el que se apoyaban. Esta circunstancia había dificultado la tarea de imponer el orden en los tumultuosos meses que siguieron a la muerte del rey Felipe. De ahí que a mediados del año 1507 una de las primeras órdenes que desde la Corte se transmitieron al juez pesquisidor enviado a Ávila, el licenciado Villafañe, fuese la de hacer tapiar los postigos abiertos en la muralla, para que nadie pudiese utilizarlos para entrar o salir de la ciudad esquivando los controles impuestos por los oficiales de la justicia del rey ${ }^{22}$.

En períodos de estabilidad y fortaleza del poder monárquico, las decisiones tomadas por las autoridades habrían bastado para asegurar el mantenimiento del orden y evitar

19 AGS, Cámara-Pueblos, Ávila, fol. 266, Ávila, 28-II-1505.

20 Diago Hernando, Máximo. «Conflictos políticos en Ávila en las décadas precomuneras». Cuadernos Abulenses, 1993, vol. 19, pp. 69-101, en particular pp. 70-82; y TAPIA SÁNCHEZ, «Ávila en la encrucijada», pp. 152-163.

21 AGS, RGS, VI-1507. Provisión a Elvira de Zúńiga, Hernán Álvarez de Toledo, Fernán Gómez de Ávila y sus seguidores, ordenándoles que hagan guardar las treguas.

22 AGS, RGS, VI-1507. 
MÁXIMO DIAGO HERNANDO

306

CONFLICTOS VIOLENTOS EN EL SENO DE LAS OLIGARQUÍAS DE LAS CIUDADES CASTELLANAS

A FINES DE LA EDAD MEDIA: LOS «BANDOS» DE ÁVILA

que las rencillas existentes en el seno del grupo oligárquico abulense desencadenasen peligrosos procesos de violencia. Pero la ausencia de un poder «fuerte» en la Corte favoreció la adopción de comportamientos temerarios y desafiantes por parte, sobre todo, de miembros de la alta nobleza y de las oligarquías urbanas a todo lo largo y ancho del reino. En Ávila, en concreto, fueron los miembros de mayor rango del grupo oligárquico los que entonces desobedecieron reiteradamente las órdenes de los representantes de la Monarquía para que se abstuviesen de comportamientos violentos, observasen las treguas que habían sido decretadas y saliesen de la ciudad, instalándose en algún lugar de sus señoríos, a fin de eliminar las ocasiones de enfrentamiento ${ }^{23}$. El que, según las informaciones disponibles, adoptó una actitud de más pertinaz desobediencia fue el señor de Villatoro, Fernán Gómez Dávila, quien, habiendo salido de Ávila en cumplimiento de las órdenes recibidas, regresó muy poco después al frente de un gran número de gente armada, de a pie y de a caballo, con la cual, el 10 de junio de 1507, se apoderó de las puertas de entrada abiertas en la muralla y, a continuación, atacó con furor las casas principales de doña Elvira de Zúñiga, causando en ellas daños materiales de consideración. Y los hombres de su clientela, no contentos con esto, también causaron dańos importantes a su paso en el monasterio premonstratense de Sancti Spiritus, sin que resulte fácil explicar por qué lo eligieron como objeto de sus ataques24.

La gravedad de los desórdenes ocurridos a principios de junio de 1507 motivó el inmediato envío desde la Corte de un alcalde de la Audiencia de Valladolid, el licenciado Carvallido, para que derramase todas las gentes de armas que se habían reunido por los dos bandos y además hiciese pesquisa juntamente con el juez de residencia comisionado con anterioridad, el licenciado Villafañ $e^{25}$. Pero, dado que se preveía que la tarea de estos dos no iba a ser fácil, al mismo tiempo se impartieron órdenes para que la gente de armas de la capitanía de Pedro López de Padilla les prestase la ayuda requerida para el desempeño de sus funciones de pesquisa y pacificación ${ }^{26}$. Además, como medida de precaución, se dirigieron cartas a varios de los principales miembros de la alta nobleza de la región conminándoles a que bajo ningún concepto prestasen ayuda a cualquiera de las dos partes en contienda, como al parecer tenían intención de hacer algunos de ellos ${ }^{27}$.

Las fuentes documentales no dejan constancia de que ninguno de estos miembros de la alta nobleza llegase a implicarse directamente en los desórdenes que tuvieron lugar en Ávila en el transcurso del año 1507, aunque con posterioridad sí se les llegó a atribuir una relevante participación a algunos de ellos. En concreto, lo hizo el monje premonstratense que escribió el becerro del monasterio de Sancti Spiritus en 1586, quien al referirse

23 AGS, RGS, V-1507. Se ordena al licenciado Villafańe que notifique a Fernán Gómez Dávila y a Fernán Álvarez de Toledo que tengan como cárcel las villas de Villatoro o Navamorcuende, el primero, y las de Villafranca o Las Navas, el segundo.

24 Sobrino Chomón, Tomás. «El monasterio premonstratense de Sancti Spiritus». Cuadernos Abulenses, 1993, vol. 19, pp. 11-39, en particular pp. 18-19.

25 AGS, RGS, VI-1507.

26 AGS, RGS, VI-1507.

27 Provisión dirigida a Diego López Pacheco, marqués de Villena y duque de Escalona, en AGS, RGS, VI-1507. Otras semejantes se enviaron a los duques de Alba, Alburquerque y Béjar, al conde de Oropesa y a los marqueses de Moya. 
MÁXIMO DIAGO HERNANDO

CONFLICTOS VIOLENTOS EN EL SENO DE LAS OLIGARQUÍAS DE LAS CIUDADES CASTELLANAS A FINES DE LA EDAD MEDIA: LOS «BANDOS» DE ÁVILA

a estos sucesos sostiene que en aquella ocasión vinieron a Ávila el duque de Béjar y el duque de Alburquerque ${ }^{28}$. Es muy probable que se trate de un error, pues en la documentación de archivo solo ha quedado constancia de la participación directa de un miembro del linaje de La Cueva, el señor de La Adrada, Antonio de la Cueva, cuñado de Fernán Gómez Dávila, cuyo nombre figura en la relación de condenados.

En cualquier caso, a la hora de valorar la implicación de la alta nobleza en los sucesos de Ávila de 1506-1507 se ha de destacar que, a diferencia de lo que ocurrió en otras grandes ciudades, como Córdoba, Sevilla, Cuenca o Toledo, en la ciudad del Adaja los que dieron origen a los disturbios fueron miembros de la nobleza media abulense, que arrastraron a los miembros de la alta nobleza con los que mantenían vínculos de afinidad política, amistad y parentesco, pero no fueron estos últimos los que con sus actuaciones desencadenaron las luchas. Monsalvo Antón destaca como rasgo original de las estructuras sociopolíticas de Ávila a fines del Medievo la ausencia en su vida política de las que él denomina «injerencias bastardas» de los linajes de alta nobleza detectadas en otras muchas ciudades realengas. Y explica este fenómeno como consecuencia de que los bandoslinajes abulenses estuvieron liderados por regidores que eran además señores de vasallos, es decir, por una nobleza señorial que actuaría como escudo frente a las ambiciones intervencionistas de los grandes señores nobles de la región ${ }^{29}$. Pero esta argumentación tiene sus puntos débiles, pues la presencia de señores de vasallos entre los regidores de las ciudades realengas castellanas del siglo Xv fue un fenómeno bastante generalizado, en absoluto exclusivo de Ávila. A nuestro juicio el rasgo que más contribuye a singularizar a las dos casas que a fines del Medievo ocupaban la cúspide de la jerarquía sociopolítica abulense es que mantenían una relación con los linajes de alta nobleza mucho menos marcada por el signo de la dependencia que la habitual entre las familias de nobleza media que daban cuerpo a las oligarquías urbanas. Así lo sugieren las alianzas matrimoniales que con ellos lograron concertar ${ }^{30}$. Pero, en cualquier caso, de esta relación menos desigual establecida entre dichas casas y la alta nobleza regional no se derivó garantía alguna para la sociedad política abulense de quedar impermeabilizada ante las pretensiones de injerencia de esta última. Buena prueba es que en 1507 se temió que miembros muy destacados de la alta nobleza se implicasen directamente en los conflictos desatados en la ciudad del Adaja. E incluso en la memoria colectiva quedó el confuso recuerdo de que el duque de Béjar había intervenido de hecho.

Durante los ańos 1506 y 1507 se cometieron en Ávila graves acciones de desacato a los oficiales de la justicia que representaban a la autoridad monárquica, que en bastantes casos supusieron una flagrante violación de las treguas decretadas por dichos oficiales. Por

28 Sobrino Chомón, «El monasterio premonstratense», p. 19.

29 Monsalvo Antón, «El realengo», p. 128.

30 La esposa de Fernán Gómez Dávila, seńor de Villatoro, era hija del duque de Alburquerque, y la de Esteban Dávila, señor de Las Navas, hermana del duque de Béjar, Don Álvaro. Pedro Dávila, padre de Esteban Dávila, había casado con una hija del señor de Oropesa. Vid. Merino Álvarez, Abelardo. La sociedad abulense durante el siglo XVI: la nobleza. Discursos leidos ante la Real Academia de la Historia en la recepción pública del señor don Abelardo Merino Álvarez. Madrid: Imprenta del Patronato de Huérfanos de los Cuerpos de Intendencia e Intervención Militares, 1926, p. 43; y Ariz, Luis. Historia de las grandezas de la ciudad de Ávila. Alcalá de Henares: Luys Mrtínez Grande, 1607. 
MÁXIMO DIAGO HERNANDO 308

CONFLICTOS VIOLENTOS EN EL SENO DE LAS OLIGARQUÍAS DE LAS CIUDADES CASTELLANAS A FINES DE LA EDAD MEDIA: LOS «BANDOS» DE ÁVILA

ello, cuando, tras el regreso de Fernando el Católico para hacerse cargo del gobierno de Castilla en nombre de su hija, se produjo un evidente fortalecimiento de las instituciones de gobierno de la Monarquía, estas tomaron varias iniciativas para desincentivar futuras tentaciones de desobediencia.

En concreto, se mostró especial interés en asegurar que el culpable del saqueo y la destrucción de las casas de Elvira de Zúńiga no escapase al merecido castigo, recurriendo al socorrido subterfugio de acogerse a la jurisdicción eclesiástica, con el argumento de haber recibido las órdenes menores. Nos consta, en efecto, que el rey se implicó personalmente en este asunto, enviando contundentes instrucciones en mayo de 1508 a su embajador en la Curia romana, Jerónimo de Vic, para que hiciese las gestiones precisas a fin de que Fernán Gómez Dávila, y los demás partícipantes en el robo de las casas de la viuda de don Esteban Dávila, pudiesen ser juzgados y castigados por los tribunales seculares y se les negase el derecho a acogerse a la jurisdicción eclesiástica, como pretendían $^{31}$. El monarca recordaba en sus instrucciones que los delitos cometidos por el señor de Villatoro con sus secuaces durante el verano de 1507 habían sido "graves y enormes», de tal envergadura que como consecuencia de los mismos la ciudad de Ávila había estado a punto de «perderse».

Esta insistencia del monarca por asegurar que el señor de Villatoro y los miembros de su clientela fuesen castigados y no pudiesen gozar del privilegio clerical, ha de explicarse ante todo como muestra de su compromiso en la defensa de la jurisdicción secular frente a la eclesiástica, del que dio repetidas pruebas. Pero la dureza de la represalia que la Monarquía quiso ejercer contra este poderoso y turbulento caballero no solo se manifestó en el empeńo puesto en hacerle comparecer ante los tribunales seculares, sino también en la extrema dureza de las penas que inicialmente los oficiales de la justicia del rey llegaron a dictar contra ellos. El proceso judicial ciertamente se demoró durante bastante tiempo y, conforme este iba transcurriendo, las penas impuestas a los condenados se iban progresivamente suavizando, hasta el punto de que para muchos terminaron resultando de facto casi irrelevantes ${ }^{32}$. Así, por lo que toca al propio Fernán Gómez Dávila, se ha de destacar que, si bien en un primer momento fue condenado a muerte, pronto consiguió que esta pena se le conmutase y que no conllevase la confiscación de su patrimonio, aunque, por el contrario, sí se le obligó a indemnizar a la parte contraria por los cuantiosos daños causados en sus casas con una elevada cantidad de dinero, fijada finalmente en 4.000 ducados, que todavía no había satisfecho cuando le llegó la muerte, y por la que hubo de responder su hermano y sucesor, Diego Fernández Dávila ${ }^{33}$. Su posición sociopolítica no quedó, sin embargo, irremediablemente dañada, pues continuó al servicio de la Monarquía, aunque con el importante matiz de que, en lugar de hacerlo en Castilla, prefirió trasladarse a Flandes, a la sombra del príncipe heredero, don Carlos, duque de Borgoña, incorporándose a

31 Rodríguez Villa, Antonio. Un cedulario del Rey Católico (1508-1509). Madrid: s.n., 1909, doc. n. ${ }^{\circ} 135$, Burgos, 14-V-1508.

32 TAPIA SÁNChez, «Ávila en la encrucijada», pp. 158-163. La ejecutoria expedida a petición de Elvira de Zúniga, en AGS, RGS, IV-1512.

33 AGS, RGS, VI-1512. 
MÁXIMO DIAGO HERNANDO

CONFLICTOS VIOLENTOS EN EL SENO DE LAS OLIGARQUÍAS DE LAS CIUDADES CASTELLANAS A FINES DE LA EDAD MEDIA: LOS «BANDOS» DE ÁVILA

sus ejércitos, que sostenían guerra contra el duque de Güeldres, donde encontró la muerte en una acción militar ${ }^{34}$.

Tanto el interés puesto por Fernando el Católico por someter a los tribunales seculares al señor de Villatoro, como la dureza del castigo que en un primer momento se le impuso e incluso su posterior marcha a Flandes para hacer méritos ante el heredero de la Corona, podrían ser interpretados como indicios de que este personaje había actuado en Ávila como dirigente de los «antifernandistas», que por este motivo habría entrado en conflicto con la facción favorable al rey de Aragón, en la que militaría la casa de Villafranca. A este respecto se ha de tener en cuenta que en algunas importantes ciudades se desencadenaron entre los años 1505 y 1508 conflictos de bandos en el seno de los grupos oligárquicos como consecuencia del enfrentamiento entre profernandistas y antifernandistas. Tal sería el caso, entre otros, de Madridd ${ }^{35}$, Cuenca ${ }^{36}$, o Toledo ${ }^{37}$. Pero por lo que toca a Ávila, en el estado actual de la investigación, no disponemos de pruebas concluyentes que permitan advertir entre los dirigentes de las facciones abulenses una clara toma de partido en las disputas sucesorias que se desencadenaron tras 1504. La dureza del castigo impuesto inicialmente a Fernán Gómez Dávila podría inducir a pensar que se había tratado de un comprometido felipista, pero no hemos encontrado pruebas positivas que corroboren esta hipótesis, mientras que por el contrario advertimos que las medidas tomadas por las instituciones de gobierno de la Monarquía mostraron el mismo grado de dureza hacia las dos partes contendientes. Además, también contra las dos partes se pronunciaron sentencias condenatoria ${ }^{38}$, si bien todo indica que fueron mucho más duras contra el bando de Fernán Gómez Dávila porque fue el que causó daños de mayor cuantía.

Por lo tanto, consideramos de todo punto aventurado sostener que los violentos disturbios acontecidos en 1506 y 1507 en la ciudad del Adaja fueron una simple derivación de las disputas sucesorias entre partidarios y opositores al Rey Católico que en aquella coyuntura dominaron el panorama político castellano. Por el contrario, entendemos que fueron ante todo el resultado del estallido de las fuertes tensiones que la secular rivalidad entre las casas de Villatoro y Villafranca había venido generando a lo largo de

34 ArIz, Historia de las grandezas, pp. 295-296; y SÁnchez GiL, Julio. «Fernán Gómez Dávila, un miembro de la casa de Navamorcuende al servicio de la nueva milicia castellana». Cuadernos Abulenses, 2006, vol. 35, pp. 281-308.

35 Zurita, Jerónimo. Historia del rey don Hernando el Católico: De las empresas y ligas de Italia (ed. de Ángel Canellas). Zaragoza: Gobierno de Aragón, 1994, t. IV. p. 151.

36 Interpretación de los sucesos de Cuenca de 1506-1507 como fruto de la pugna entre fernandistas

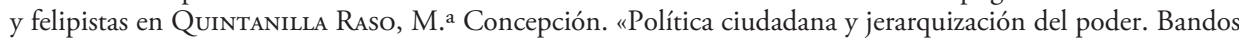
y parcialidades en Cuenca». En la España Medieval, 1997, vol. 20, p. 249. Matizaciones a esta tesis en DiAGO Hernando, Máximo. «La incidencia de los conflictos banderizos en la vida política de las ciudades castellanas a fines de la Edad Media: El caso de Cuenca». Hispania, 2009, vol. 69, n. ${ }^{2}$ 233, pp. 683-714.

37 Santa Cruz, Alonso de. Crónica del emperador Carlos V. Madrid: Real Academia de la Historia, 1920, vol. I, p. 218.

38 AGS, RGS, IV-1508. Se alude a la denuncia presentada en el Consejo por Fernán Gómez Dávila contra Fernán Álvarez de Toledo y otros caballeros de la parcialidad de Elvira de Zúñiga por haber quebrantado las treguas decretadas. También se quejó de que las sentencias pronunciadas contra Fernán Álvarez de Toledo no se habían ejecutado. 
MÁXIMO DIAGO HERNANDO

310

CONFLICTOS VIOLENTOS EN EL SENO DE LAS OLIGARQUÍAS DE LAS CIUDADES CASTELLANAS

A FINES DE LA EDAD MEDIA: LOS «BANDOS» DE ÁVILA

décadas. Y, por consiguiente, obedecieron a motivaciones preferentemente locales y no a las presiones «extraconcejiles» de las que habla el profesor Monsalvo, cuando analiza, por ejemplo, las luchas de bandos en Ciudad Rodrigo ${ }^{39}$. No podemos olvidar a este respecto que ya antes de morir la reina Isabel la existencia de tal rivalidad estaba suponiendo una grave amenaza para el orden público, como demuestran las actuaciones del ańo 1504 para derramar las gentes de armas que los mayorazgos de estas dos casas habían estado reuniendo.

Por otra parte, la resolución, aunque solo transitoria, del conflicto sucesorio, con la consolidación de Fernando el Católico al frente del gobierno de Castilla en el año 1508, tampoco puso fin en Ávila a las tensiones banderizas que tan graves desórdenes habían provocado en 1506 y 1507, sino que las mismas continuaron latentes, sin dejar de representar en ningún momento una persistente amenaza para la paz.

Para empezar, mientras se resolvían los pleitos en la parsimoniosa sede judicial, la Monarquía obligó en abril de 1508 a los cabezas de bando que permaneciesen desterrados de Ávila y sus arrabales hasta nueva orden, imponiéndoles además una tregua ${ }^{40}$. Pero aparentemente estas medidas preventivas no bastaron para evitar los desórdenes. Lo probaría la noticia que proporciona Cooper sobre un ataque que hacia 1510 estaba preparando Elvira de Zúniga contra la fortaleza de Villatoro, para el cual su hermano, el duque de Béjar, le habría facilitado ciertas piezas de artillería y hasta 1.100 hombres de $\operatorname{armas}^{41}$. Este autor interpreta el episodio como la culminación de los bandos iniciados en 1507 , presentándolo incluso como un «empeñado intento» del duque de Béjar por restablecer el predominio de los Zúñiga en Ávila ${ }^{42}$. No hay bases, sin embargo, para sostener que los duques de Béjar persiguiesen proyecto alguno de someter a su dominio la ciudad del Adaja, por lo que consideramos más acertado interpretar el mencionado ataque como una medida de represalia por la destrucción de las casas principales de Elvira de Zúniga en 1507, acometida en un momento de debilidad de la casa de Villatoro, cuando su titular estaba ausente en Flandes y había dejado el castillo de esta villa de su señorío a cargo del comendador Diego del Águila ${ }^{43}$.

Otra prueba de la persistencia de la rivalidad entre las casas de Villatoro y Villafranca en unos niveles que la convertían en una grave amenaza para el orden público durante los años predominantemente "pacíficos» de la segunda regencia de Fernando el Católico nos la proporciona la peripecia del caballero abulense Pedro del Peso. Por un memorial sin fecha, que presentó ante el Consejo Real su procurador, nos consta que fue encarcelado en Ávila por orden de Juan de Cuero, pesquisidor del rey, quien le acusó de que, como criado del señor de Villatoro, había mandado llamar a otros escuderos y criados suyos, con los que había acudido a la casa que este último tenía en Ávila, porque a la sazón había alboroto en la ciudad. Y un segundo motivo por el que le mandó detener era porque

39 Monsalvo Antón, «Las luchas de bandos en Ciudad Rodrigo», p. 214.

40 AGS, RGS, IV-1508. Provisiones dirigidas a Fernán Gómez Dávila, Elvira de Zúñiga y Fernán Álvarez de Toledo.

41 Cooper, Edward. Castillos señoriales en la Corona de Castilla. Valladolid: Junta de Castilla y León, 1991, vol. II, p. 373.

42 Cooper, Castillos, vol. I, p. 133.

43 AGS, RGS, VII-1522. Provisión a petición del comendador Diego del Águila. 
MÁXIMO DIAGO HERNANDO

CONFLICTOS VIOLENTOS EN EL SENO DE LAS OLIGARQUÍAS DE LAS CIUDADES CASTELLANAS A FINES DE LA EDAD MEDIA: LOS «BANDOS» DE ÁVILA

había mandado tomar una casa y torre que había pertenecido a Sancho Sánchez de Ávila, dejando en ella varios hombres de guarnición para que la guardasen ${ }^{44}$. Para exculparle el procurador recordó su condición de criado que recibía salario de Fernán Gómez Dávila, que como capitán de la gente de armas de este caballero había servido al rey en las guerras pasadas. Y justificó la toma que había realizado de la casa de Sancho Sánchez de Ávila argumentando que no lo había hecho con violencia y gente armada contra la voluntad de su dueño, sino de forma pacífica y legal, con el único objetivo de impedir que los criados y gentes de Pedro de Ávila la pudiesen tomar, para después «encastillarla», y utilizarla como base para atacar los intereses de su señor. Es decir, que en aquellos momentos las tensiones entre las dos grandes casas que ocupaban la cúspide del estamento caballeresco abulense seguían al rojo vivo, y por este motivo ambas partes tomaban cuantas medidas estaban a su alcance para reforzar su posición, a fin de evitar resultar sorprendidas en situación de debilidad en el caso nada improbable de que se volviesen a declarar abiertamente las hostilidades.

Solo si tenemos en cuenta esta circunstancia se explica la celeridad con la que las instituciones de gobierno de la Monarquía actuaron en enero de 1516 a raíz de producirse la muerte de Fernando el Católico, que abría un nuevo período de interinidad en la historia de la Corona de Castilla en el que resultaba previsible que el poder real volviese a experimentar de nuevo un fuerte debilitamiento. En efecto, llama la atención que ya en aquel mismo mes de enero desde el Consejo Real se expidió una provisión dirigida a Elvira de Zúniga y a su hijo Pedro de Ávila, señor de Villafranca y Las Navas, de un lado, y a Diego Fernández de Ávila, seńor de Villatoro y Navamorcuende, de otro lado, por la que se les conminaba a que abandonasen de inmediato la ciudad de Ávila y fijasen su residencia en alguno de sus lugares de señorío, con la condición de que no regresasen hasta que hubiesen obtenido licencia regia para poder hacerlo ${ }^{45}$. No cabe duda de que los sangrientos y destructivos sucesos de los años 1506 y 1507 habían dejado un muy mal recuerdo en la Corte y, conscientes de que las causas que los habían provocado no habían sido en absoluto erradicadas, resultaba imperioso actuar en esta ocasión de forma preventiva con una mayor contundencia. Y al parecer, ahora sí, dichas medidas preventivas bastaron para que no se reprodujeran los sucesos de hacía una década. De hecho, aunque todavía no hemos llevado a cabo un rastreo sistemático de la documentación, no hemos vuelto a encontrar noticias sobre sucesos violentos ocurridos en Ávila como consecuencia de la rivalidad entre las casas de Villatoro y Villafranca en los turbulentos años que precedieron al estallido de la revuelta comunera.

Además, llama la atención el hecho de que, mientras que en muchas otras grandes ciudades castellanas que habían conocido violentas luchas banderizas en las dos primeras décadas del siglo xvi tuvo lugar un evidente rebrote de las mismas en el contexto de la revuelta de las Comunidades ${ }^{46}$, nada parecido consta que sucediese en Ávila en los años

44 AGS, Cámara-Personas, leg. 21.

45 AGS, RGS, I-1516.

46 Sobre el rebrote de los bandos durante la guerra comunera vid., para Salamanca, SANTOs BURGALETA, Manuel. «"Extensiones de poder": Una propuesta de análisis en torno a la articulación de los espacios de poder. La valía del doctor Talavera en Salamanca (1475-1521)». En Bravo Lozano, Jesús. (ed.). Espacios 
MÁXIMO DIAGO HERNANDO

312

CONFLICTOS VIOLENTOS EN EL SENO DE LAS OLIGARQUÍAS DE LAS CIUDADES CASTELLANAS

A FINES DE LA EDAD MEDIA: LOS «BANDOS» DE ÁVILA

1520 y 1521 . Por el contrario, en estos dos años nada significativo encontramos en las fuentes sobre la actividad política desplegada por los señores de Villatoro y Villafranca, que según todos los indicios se mantuvieron en un discreto segundo plano y no aprovecharon la coyuntura de debilitamiento de la Monarquía para buscar la resolución por la fuerza de sus añejas diferencias, como habían tratado de hacer tras las muertes de Isabel I y Felipe $\mathrm{I}^{47}$.

La falta de noticias sobre enfrentamientos de carácter banderizo en Ávila en los años 1520 y 1521 no prueba, sin embargo, que para entonces la sociedad abulense hubiese conseguido superar de forma definitiva esta lacra. Por el contrario, poco después la documentación vuelve a proporcionar testimonios del desencadenamiento de este tipo de luchas, que, no obstante, no sabemos muy bien qué conexiones tenían con las que ocurrieron durante el período precomunero. En concreto, nos consta que en la víspera de la fiesta de la Santísima Trinidad del año 1523, por la noche, Vela Núnez, Gil González y Diego de Ávila, con otros criados del marqués de Pescara entraron en casa de Pedro de Ávila, pagador de la gente de las guardas del rey, y les dieron muchas cuchilladas a este y a otros dos que con él estaban ${ }^{48}$. Habría que realizar un detenido trabajo prosopográfico para tratar de establecer conexiones entre este episodio de violencia banderiza y los que ocurrieron en Ávila en los años 1506 y 1507. Y también habría que profundizar en la reconstrucción de la historia política abulense durante los reinados de Carlos I y Felipe II para determinar cómo fue evolucionando la rivalidad entre las casas de Villatoro y Las Navas, que tan furibundamente irreconciliables se mostraban a principios del siglo Xvi. En concreto habría que valorar la incidencia que en su disputa por la consecución de la hegemonía pudo tener la adquisición por el mayorazgo de la casa de Las Navas en la década de 1560 del oficio de alférez mayor de Ávila y su Tierra, que le aseguró a él y sus sucesores hasta el final del Antiguo Régimen un puesto preeminente en el consistorio abulense, con prerrogativas tan envidiadas en aquel tipo de sociedad como la de ser el encargado, en representación de la sociedad política abulense, de levantar el pendón en signo de proclamación del nuevo monarca cada vez que se producía un cambio en la persona que ocupaba el trono castellano ${ }^{49}$.

\footnotetext{
de poder: Cortes, ciudades y villas (S. XVI-XVIII). Madrid: J. Bravo, 2002, vol. II, pp. 73-92; y «Poderes urbanos y Comunidades de Castilla: La Junta de Salamanca a través de sus actas de sesiones (agosto de 1520-abril de 1521)». Salamanca. Revista de Estudios, 2002, vol. 48, pp. 357-441. Sobre Plasencia, Diago Hernando, Máximo. "Las luchas de bandos como factor determinante del conflicto comunero en Plasencia (1520-1522)». Cuadernos de Historia Moderna, 2006, vol. 31, pp. 63-89. Sobre Cuenca, Diago Hernando, «La incidencia de los conflictos», pp. 683-714. Para Ciudad Rodrigo, Fernández, Luis. "Feliciano de Silva y el movimiento comunero en Ciudad Rodrigo». Archivos Leoneses, 1977, vol. 62, pp. 285-358; y GonzÁlez RodríGuez, R. «Lucha de bandos y beneficios eclesiásticos en los encastillamientos de Ciudad Rodrigo (1475-1520)». Studia Historica. Historia Medieval, 1999, vol. 17, pp. 263-293. Para Sevilla interesa AGS, Cámara-Memoriales, leg. 141, fol. 238. Abundan los testimonios documentales sobre el recrudecimiento de los bandos en Úbeda y Baeza en 1520.

47 Tapia Sánchez, Serafín de. "La participación de Ávila en las Comunidades de Castilla». En Ávila en el tiempo. Homenaje al profesor Ángel Barrios. Ávila: Diputación de Ávila, 2007, vol. III, pp. 139-182; y Ruiz Ayúcar, M. ' José. «Aportación a la historia de las Comunidades en Ávila». Cuadernos Abulenses, 1987, vol. 7, pp. 219-240.

48 AGS, RGS, VI-1523 (1\%).

49 Merino Álvarez, La sociedad abulense, p. 73.
} 
MÁXIMO DIAGO HERNANDO

CONFLICTOS VIOLENTOS EN EL SENO DE LAS OLIGARQUÍAS DE LAS CIUDADES CASTELLANAS A FINES DE LA EDAD MEDIA: LOS «BANDOS» DE ÁVILA

Numerosos indicios prueban que los bandos-linaje de San Vicente y San Juan no tenían el carácter a fines del Medievo de auténticas facciones que se disputasen la primacía política en Ávila, que agrupasen a individuos que compartían unos mismos intereses y objetivos, definidos por contraposición a los de los miembros de la facción contraria. Entre ellos cabe destacar las noticias relativamente numerosas que proporciona la documentación sobre enconados conflictos que se plantearon en el seno de ambos linajes con ocasión de nombramientos de oficiales.

Eran varios los oficios que, según la constitución política de carácter consuetudinario vigente en Ávila en el período bajomedieval, debían ser designados por los dos linajes de San Vicente y San Juan, siempre a partes iguales. Entre ellos estaban las dos escribanías del ayuntamiento, que tenían carácter vitalicio. En principio tenían reconocido derecho a participar en la elección del nuevo escribano todos los regidores del correspondiente linaje, pero esta norma no fue universalmente admitida y por ello se plantearon graves conflictos en el seno de los propios linajes. Ocurrió, por ejemplo, en el año 1493, cuando quedó vacante la escribanía de concejo que correspondía proveer al linaje de San Juan. Entonces uno de los regidores, Pedro de Ávila, señor de Villafranca, por sí solo, y encontrándose además fuera de la ciudad, procedió a nombrar al nuevo escribano, provocando de este modo la oposición de otros varios regidores del linaje, que recurrieron ante el Consejo Real, denunciando la invalidez del nombramiento por haberse realizado de forma irregular ${ }^{50}$.

De hecho, los titulares del mayorazgo de Villafranca-Las Navas defendieron en repetidas ocasiones la tesis de que ellos tenían reconocida en el seno del linaje de San Juan una posición de preeminencia equivalente a la que ocupaban en el seno del linaje de San Vicente los titulares del mayorazgo de Villatoro- Navamorcuende, que les facultaba para proceder ellos por sí solos a la elección de determinados oficiales. Y, en efecto, por muy diversas razones resulta evidente que estos dos mayorazgos ocupaban en el seno del grupo caballeresco abulense una posición singular, que se traducía, por ejemplo, en el disfrute de ciertas prerrogativas, que no compartían con otros linajes de acreditada solera de la sociedad abulense, como es el caso, por ejemplo, del privilegio de percibir por virtud de merced regia los derechos de las «entregas y ejecuciones de los contratos y cartas públicas de la ciudad y su Tierra ${ }^{51}$. Esta circunstancia les predisponía para asumir funciones de liderazgo, con mayor razón aún debido a que en la ciudad del Adaja no llegaron a arraigar linajes de alta nobleza que pudiesen disputarles el desempeño de tal papel, a diferencia de lo que ocurrió en otras muchas grandes ciudades castellanas ${ }^{52}$.

Serafín de Tapia sostiene que la autoridad moral de los seńores de Villafranca y Villatoro era habitualmente reconocida por todos, porque ellos garantizaban que hubiese

50 AGS, RGS, XII-1493, fol. 49.

51 AGS, RGS, IV-1514.

52 Diago Hernando, Máximo. «La participación de la nobleza en el gobierno de las ciudades europeas bajomedievales. Análisis comparativo». Anuario de Estudios Medievales, 2007, vol. 37/2, pp. 781-822; ÍDEM. «Intervencionismo de la alta nobleza en la vida política de las ciudades castellanas a fines de la Edad Media: Los mariscales de Castilla en Soria». Edad Media. Revista de Historia, 2014, vol. 15, pp. $245-271$. 
MÁXIMO DIAGO HERNANDO

314

CONFLICTOS VIOLENTOS EN EL SENO DE LAS OLIGARQUÍAS DE LAS CIUDADES CASTELLANAS

A FINES DE LA EDAD MEDIA: LOS «BANDOS» DE ÁVILA

una distribución equilibrada de las prebendas entre los componentes de la oligarquía lo$\mathrm{cal}^{53}$. Pero abundan las pruebas de que tal autoridad no era en la práctica tan incontestada. El episodio de 1493 que acabamos de analizar nos proporciona una, y a continuación daremos cuenta de otras más.

Así en 1502 volvió a plantearse otro conflicto por la designación del escribano del concejo, aunque en esta ocasión en el seno del linaje de San Vicente, tras el fallecimiento de Fernán Sánchez de Pareja ${ }^{54}$. Entonces el señor de Villatoro, Fernán Gómez Dávila, no quiso, sin embargo, apelar a pretendidos privilegios reconocidos a su casa por costumbre inmemorial para poder nombrar por sí solo al nuevo escribano. Parece que hubo acuerdo en que procedía elegir mediante votación entre todos los regidores del linaje presentes en la sesión del concejo señalada para ello. Pero existía división de opiniones entre ellos, mostrándose divididos en dos facciones que desde el primer momento maniobraron para tratar de imponer a su candidato. Así, en la sesión de concejo de 12 de noviembre de 1502 el regidor Gonzalo Sánchez Dávila requirió al corregidor para que, debido a que muchos regidores estaban ausentes de la ciudad y otros varios se deberían ausentar, por haber sido requeridos para acudir a la Corte, se prescindiese de momento de elegir al nuevo escribano y se esperase al momento en que hubiese mayor concurrencia de regidores, pues convenía que dicha escribanía fuese proveída «a votos de todos los regidores del linaje o de la mayor parte, y no solapadamente». La solicitud no fue, sin embargo, atendida, y en sesión celebrada pocos días después Fernán Gómez Dávila procedió a nombrar a Juan Álvarez de Revenga, sumándose a su voto su sobrino, Fernán Gómez Dávila, y Francisco de Henao, por sí mismo y con poder de Suero del Águila, que estaba ausente en la Corte. Esta elección fue, sin embargo, inmediatamente contradicha por Gonzalo Sánchez Dávila, alegando que no habían sido convocados la mayoría de los regidores del linaje, de entre los que hizo mención expresa a Diego Álvarez de Bracamonte y Gonzalo del Peso, mientras que por el contrario se había aceptado la validez del voto de un ausente, Suero del Águila. Aquel día no se tomó todavía ninguna decisión, pero al día siguiente volvió a repetirse la misma operación, obteniendo Juan Álvarez de Revenga los mismos votos que el día anterior. Por consiguiente, el corregidor terminó confirmando su elección por haber obtenido mayoría de votos, desatendiendo las denuncias de Gonzalo Sánchez Dávila, que acusaba a sus contrarios de haber amańado la elección, por haber esperado al momento en que varios regidores estaban ausentes de la ciudad para proceder a la misma a fin de asegurarse la mayoría de votos.

Dos nuevos litigios por la designación de otros oficiales se plantearon en el seno del linaje de San Vicente a lo largo del año 1508, en los que encontramos implicados los mismos actores que en el de 1502 que acabamos de analizar. El primero surgió con motivo de la elección del alcalde de Hermandad. Los mayorazgos de las casas de Villatoro y Las Navas sostenían que a ellos les correspondía todos los años elegir un alcalde de Hermandad el día de la fiesta de la Virgen de agosto, un ańo entre los miembros del estamento pechero y al siguiente entre los del estamento hidalgo. En el linaje de San Vicente, sin

53 TAPIA SÁNCHEZ, «Ávila en la encrucijada», p. 153.

54 Nos basamos en documentación trasladada en AChV (= Archivo de la Chancillería de Valladolid), P.C. (= Pleitos Civiles), Fernando Alonso, F. (= Fenecidos), C. (= Caja) 688-1. 
MÁXIMO DIAGO HERNANDO

CONFLICTOS VIOLENTOS EN EL SENO DE LAS OLIGARQUÍAS DE LAS CIUDADES CASTELLANAS A FINES DE LA EDAD MEDIA: LOS «BANDOS» DE ÁVILA

embargo, en 1508 fueron los regidores Diego Álvarez de Bracamonte, señor de Fuentesol, y Cristóbal del Peso los que por su propia iniciativa procedieron a la elección de Luis del Castillo como alcalde de Hermandad de los pecheros, tropezando luego con la oposición del corregidor, Gómez de Santillán, quien antes de admitirle manifestó que necesitaba recibir información sobre él, a lo que Diego Álvarez de Bracamonte replicó que no había lugar tal exigencia puesto que los regidores podían nombrar a quien quisiesen ${ }^{55}$. El corregidor persistió en su negativa, y por ello los dos mencionados regidores recurrieron a la Chancillería de Valladolid, que al parecer se inclinó a concederles la razón. Al menos es lo que ambos sostuvieron pocos meses después, cuando volvió a plantearse de nuevo un pleito por la designación del letrado del concejo en el seno del mismo linaje.

Este segundo litigio se originó a raíz de que estos dos regidores procediesen a elegir como nuevo letrado del concejo al licenciado Pedro Vázquez, a lo que de inmediato se opuso la parte de la casa de Villatoro ${ }^{56}$. En aquellos momentos, no obstante, el titular de la casa no se encontraba en Ávila, pues había marchado a Flandes a servir en la guerra al príncipe Carlos. Fue, por consiguiente, su esposa, doña Brianda de la Cueva, quien asumió la defensa de los intereses del marido ausente. Y lo hizo apelando a la costumbre inmemorial, según la cual el regidor y principal pariente del linaje de San Vicente, el señor de la casa de Villatoro, tenía reconocida la prerrogativa de nombrar a las personas que habían de desempeñar los cuatro oficios de escribano, letrado, mayordomo y procurador del concejo, como lo habían hecho hasta entonces su marido y, antes de él, su padre, Gonzalo de Ávila, y su abuelo, el doctor Pedro González Dávila. Además, añadió que este mismo derecho había correspondido al regidor y pariente principal del linaje de San Juan, señor de la casa de Villafranca.

Diego Álvarez de Bracamonte y Cristóbal del Peso rechazaron, sin embargo, la validez de este argumento, reafirmándose por el contrario en las tesis que ya habían mantenido meses antes para justificar la validez de la elección que ellos mismos habían efectuado de Luis del Castillo como alcalde de Hermandad. Según ellos, todos los regidores del linaje de San Vicente debían participar en la designación del letrado, sin reconocer en este punto privilegio alguno a la casa de Villatoro. Además, entendían que para que la elección fuese válida bastaba con que el designado hubiese obtenido una mayoría de votos de los regidores presentes en la reunión de ayuntamiento en que se procediese a la misma, sin tener en cuenta la opinión de los ausentes. Y daban por sobreentendido que dichos regidores podían nombrar a la persona que estimasen conveniente, sin tener en cuenta su adscripción a uno u otro linaje.

Cada parte recurrió a los argumentos que más le acomodaban, pero la falta de ordenanzas en que hubiesen quedado regulados los procedimientos electorales, sustituidas por las meras apelaciones a la costumbre inmemorial, dejaba abierta la puerta a las discrepancias. De hecho, las dos partes, mediante declaraciones de testigos y presentación de testimonios documentales que daban fe sobre cómo se había procedido con anterioridad al nombramiento de muy diversos oficiales, aportaron pruebas que, si algo dejaron claro, es que en el pasado no se había seguido un procedimiento uniforme.

55 AGS, Cámara-Pueblos, Ávila, fol. 232. Ávila, 19-VIII-1508.

56 AChV, P.C., Fernando Alonso, F., C. 688-1. 
MÁXIMO DIAGO HERNANDO

316

CONFLICTOS VIOLENTOS EN EL SENO DE LAS OLIGARQUÍAS DE LAS CIUDADES CASTELLANAS

A FINES DE LA EDAD MEDIA: LOS «BANDOS» DE ÁVILA

Pero del análisis de la abundante documentación generada por la tramitación de este pleito cabe concluir que los linajes de San Vicente y San Juan no constituían a principios del siglo Xvi bloques homogéneos que agrupasen a un importante número de familias de caballeros unidas por una misma filiación política, o por relaciones de dependencia clientelar respecto a las casas de Villatoro y Villafranca. La misma demuestra, por el contrario, que en el seno de cada linaje coexistían familias ferozmente enfrentadas entre sí, que tomaron parte muy activa en los más sangrientos episodios vividos por la ciudad de Ávila a principios del siglo Xvi.

En efecto, los motivos por los que dońa Brianda de la Cueva se opuso en 1508 a la elección de letrado efectuada por Diego Álvarez de Bracamonte y Cristóbal del Peso, tenían que ver no tanto con el hecho de que en la misma se hubiese dejado de observar la costumbre inmemorial, sino mucho más con la circunstancia de que los dos regidores que habían designado al candidato por ella rechazado se contaban entre los más estrechos aliados de sus más acérrimos enemigos, doña Elvira de Zúñiga y su hijo Pedro de Ávila, con los que hacía pocos meses se había enfrentado furiosamente su marido en las calles de Ávila. De hecho, doña Brianda llegó a sugerir abiertamente que la mencionada elección no tenía otro objetivo que dañar los intereses de la casa de Villatoro, aprovechando un momento de debilidad de la misma, resultado de la ausencia de su dirigente, desplazado a las lejanas tierras flamencas en servicio del rey. Y no resulta en absoluto inverosímil que así fuese. Pero lo que más llama la atención de este caso es que Diego Álvarez de Bracamonte y Cristóbal del Peso, dos destacados miembros de la oligarquía abulense, formaban parte del mismo linaje que el mayorazgo de la casa de Villatoro contra la que dirigían sus dardos, el de San Vicente, al tiempo que tenían establecida una estrecha relación de amistad con los miembros principales de la casa de Villafranca, que estaban al frente del linaje contrario, el de San Juan. Prueba más que elocuente de que ambos linajes no constituían auténticas facciones o bandos a principios del siglo XVI.

Por lo demás, conflictos semejantes siguieron planteándose en los ańos siguientes. Así, en 1513 en el linaje de San Vicente volvió a surgir otro por la elección del alcalde de Hermandad. Entonces el nuevo señor de Villatoro, Diego Fernández Dávila, con el apoyo de los regidores Fernán Gómez Dávila, hijo del comendador Francisco Dávila, y Sancho Zimbrón, designaron para este oficio al hidalgo Juan de Ávila, pero por su parte los regidores Diego Álvarez de Bracamonte, Sancho Sánchez y Cristóbal del Peso eligieron a Gil Juárez ${ }^{57}$. El señor de Villatoro descalificó a este último por llevar acostamiento del duque del Infantado, por ejercer el oficio de procurador, estando prohibido desempeñar dos oficios públicos simultáneamente, y, por fin, por ser miembro del linaje de San Juan. Pero, por si estos argumentos resultaban insuficientes, ańadió que, en el hipotético caso de que los electos tuviesen paridad de votos y calidad, era preferido el designado por el señor de la casa de Villatoro. Es decir, que aquí se mitigaba bastante el alcance de la posición privilegiada que dicha casa pretendía ocupar en el seno del linaje de San Vicente, al reconocer también al resto de los regidores del linaje el derecho a participar en la elección de los oficiales, reservando solo al señor de Villatoro la prerrogativa de resolver los empates con su voto de calidad. Pero ni siquiera esto estaban ya dispuestos a admitir

57 AGS, RGS, IX-1513; y Diago Hernando, «Conflictos políticos en Ávila», pp. 99-100. 
MÁXIMO DIAGO HERNANDO

CONFLICTOS VIOLENTOS EN EL SENO DE LAS OLIGARQUÍAS DE LAS CIUDADES CASTELLANAS A FINES DE LA EDAD MEDIA: LOS «BANDOS» DE ÁVILA

los regidores que una vez tras otra se posicionaron contra los candidatos propuestos por dicha casa a principios del XvI, que se aferraron al principio de que todos los votos de los regidores del linaje eran iguales, y de que estos tenían libertad de elegir a quien estimasen oportuno, sin tomar en consideración la pertenencia de los candidatos a uno u otro linaje. Pero no resultaba fácil determinar a quién asistía la razón, porque todos apelaban a la costumbre inmemorial y no había ningún texto escrito en que los procedimientos de elección de oficiales hubiesen quedado pormenorizadamente regulados.

\section{Conclusión}

Con las informaciones aportadas ha podido quedar demostrado que a fines del Medievo los dos linajes de San Vicente y San Juan no constituían en Avila dos facciones jerárquicamente organizadas, en las que múltiples familias coexistiesen bajo el firme liderazgo de dos prestigiosas y acaudaladas casas de mediana nobleza, muy vinculadas con familias principales de la alta nobleza por lazos de parentesco. Por múltiples razones el lugar ocupado por cada una de estas casas en su respectivo linaje era preeminente, y ninguna otra familia podía disputárselo. Pero en el seno de cada uno de los dos linajes se habían desarrollado poderosos movimientos de oposición al liderazgo de ambas casas.

$\mathrm{Al}$ analizar el violento enfrentamiento entre los dos bandos encabezados por los seńores de Villatoro y de Villafranca en 1506 y 1507, el profesor De Tapia, cuando pasa revista a los individuos que militaron en cada uno de los bandos, se muestra sorprendido al constatar que en el liderado por el de Villatoro estuvieron dos caballeros que formaban parte del linaje de San Juan, Nuño González del Águila y Francisco González, señor de Cespedosa. Y admite que no se encuentra en disposición de ofrecer una explicación convincente a este hecho ${ }^{58}$. Pero, en función de cuanto llevamos dicho, el fenómeno no tiene nada de extraño o ilógico. Por el contrario, hemos podido constatar también que, a la inversa, varios destacados caballeros que en 1506 y 1507 apoyaron al bando de Elvira de Zúńiga estaban integrados en el linaje de San Vicente y se opusieron sistemáticamente al señor de Villatoro en varias elecciones de oficiales que correspondió realizar a este en las dos primeras décadas del siglo xvi. Es decir, que las líneas que definían a las facciones que se disputaban el poder político y la influencia social en Ávila en esta época no coincidían con las que, al menos desde el siglo XIV, venían separando a las familias agrupadas en el linaje de San Vicente, por un lado, y las agrupadas en el de San Juan, por otro.

$\mathrm{Al}$ mismo tiempo, ha podido quedar demostrado que la rivalidad existente entre las casas de Villatoro y Villafranca fue el principal factor de inestabilidad de la vida política en Ávila a fines del Medievo. La capacidad de arrastre que dichas casas tenían resulta incuestionable, y quedó bien puesta de manifiesto en los años 1506 y 1507, durante los que el peligro de que la anarquía se apoderase de la ciudad del Adaja fue grande. Uno de los principales problemas que se plantea es el de determinar cuáles eran los motivos fundamentales que explicarían dicha persistente rivalidad que recorre los siglos. De Tapia apunta su posible relación con la competencia por la apropiación de tierras en el alfoz

58 Tapia SÁncheZ, «Ávila en la encrucijada», p. 161. 
MÁXIMO DIAGO HERNANDO

318

CONFLICTOS VIOLENTOS EN EL SENO DE LAS OLIGARQUÍAS DE LAS CIUDADES CASTELLANAS

A FINES DE LA EDAD MEDIA: LOS «BANDOS» DE ÁVILA

abulense ${ }^{59}$. Pero, sin negar la importancia de este factor, también habría que tener muy en cuenta otro relacionado con la mentalidad caballeresca que ambicionaba la preeminencia a toda costa, considerando deshonroso todo lo que la pusiese en cuestión. Es la idea que se resume en las palabras del monje premonstratense que escribió el becerro del monasterio de Sancti Spiritus en 1586, el cual, al referirse a los sucesos de 1507, sostuvo que se debieron a "cuestiones heredadas de padres a hijos y nietos, porque los señores de entrambas casas han sido siempre en esta ciudad muy poderosos, y el señorear nunca sufre igual» ${ }^{60}$.

En efecto, las ciudades realengas castellanas de fines del Medievo estaban gobernadas por caballeros fuertemente imbuidos de una mentalidad nobiliaria, muchos de los cuales disponían de sus propios seńoríos, donde ellos podían ejercer el poder de forma plena, por derecho de sangre, sin que nadie les hiciese sombra, aunque respetando por supuesto las normas impuestas por la Monarquía, con mayor eficacia en unos momentos que en otros. Pero en las ciudades esos caballeros se veían forzados a ejercer el poder de forma colegiada, a través de una institución, el regimiento, en la que tenían que compartir el poder con otros. Su mentalidad nobiliaria no les predisponía ciertamente a compartir, ni a colaborar con aquellos a los que se resistían a considerar como sus iguales. Siempre estaba presente el afán de sobresalir por encima de los demás, y aquí habría que ver el origen de muchos de los desórdenes que vivieron las ciudades castellanas hasta bien entrado el siglo XVI. Los historiadores de las últimas generaciones hemos tendido a olvidar con cierta frecuencia que las pasiones humanas también han desempeñado un importante papel en la historia y contribuido a privar de «racionalidad» a muchos procesos, al menos de la racionalidad tal como queda definida en los modelos lógico-deductivos. Así, desde ciertos presupuestos, puede parecer carente de «lógica» que las casas de Villatoro y Villafranca mantuviesen una relación de mutua hostilidad a lo largo de varias generaciones, cuando la necesidad de defender sus intereses les hubiese debido llevar a colaborar para hacer frente al posible desafío de los grupos sociales mayoritarios a los que tenían sometidos a una relación de explotación. Pero los documentos confirman una y otra vez que dicha relación de hostilidad existió y que en más de una ocasión dio lugar a la erupción de episodios de violencia más o menos destructiva. La violencia formó parte de la vida cotidiana en muchas ciudades, y no se ejerció solo por los privilegiados sobre los grupos populares. El énfasis puesto por los estudiosos en el análisis de las estrategias de pacificación y de búsqueda del consenso no debería hacérnoslo olvidar.

\section{REFERENCIAS BIBLIOGRÁFICAS}

Ariz, Luis. Historia de las grandezas de la ciudad de Avila. Alcalá de Henares: Luys Mrtínez Grande, 1607.

Bilinkoff, Jodi. The Avila of St. Teresa. Religious Reform and Urban Development, 1480-1620. Ann Arbor: University Microfilms International, 1983.

59 TAPIA SÁnchez, "Ávila en la encrucijada», pp. 153 y 157.

60 Sobrino Сhomón, «El monasterio premonstratense», p. 19. 
MÁXIMO DIAGO HERNANDO

CONFLICTOS VIOLENTOS EN EL SENO DE LAS OLIGARQUÍAS DE LAS CIUDADES CASTELLANAS

A FINES DE LA EDAD MEDIA: LOS «BANDOS» DE ÁVILA

Cooper, Edward. Castillos señoriales en la Corona de Castilla. Valladolid: Junta de Castilla y León, 1991.

Diago Hernando, Máximo. «Conflictos políticos en Ávila en las décadas precomuneras». Cuadernos Abulenses, 1993, vol. 19, pp. 69-101.

Diago Hernando, Máximo. «Intervencionismo de la alta nobleza en la vida política de las ciudades castellanas a fines de la Edad Media: Los mariscales de Castilla en Soria». Edad Media. Revista de Historia, 2014, vol. 15, pp. 245-271.

Diago Hernando, Máximo. «La alta nobleza en la vida política de las ciudades castellanas en las décadas precomuneras: el ejemplo de Cuenca (1506-1507)». Cuadernos de Historia Moderna, 1994, vol. 15, pp. 121-141.

Diago Hernando, Máximo. «La incidencia de los conflictos banderizos en la vida política de las ciudades castellanas a fines de la Edad Media: El caso de Cuenca». Hispania, 2009, vol. 69, n. ${ }^{\circ} 233$, pp. 683-714.

Diago Hernando, Máximo. «La participación de la nobleza en el gobierno de las ciudades europeas bajomedievales. Análisis comparativo». Anuario de Estudios Medievales, 2007, vol. 37/2, pp. 781-822.

Diago Hernando, Máximo. «Las luchas de bandos como factor determinante del conflicto comunero en Plasencia (1520-1522)». Cuadernos de Historia Moderna, 2006, vol. 31, pp. 63-89.

FERnÁNDEZ, Luis. "Feliciano de Silva y el movimiento comunero en Ciudad Rodrigo». Archivos Leoneses, 1977, vol. 62, pp. 285-358.

González Rodríguez, R. «Lucha de bandos y beneficios eclesiásticos en los encastillamientos de Ciudad Rodrigo (1475-1520)». Studia Historica. Historia Medieval, 1999, vol. 17, pp. 263-293.

Jara Fuente, José Antonio. Concejo, poder y élites. La clase dominante de Cuenca en el siglo XV. Madrid: Consejo Superior de Investigaciones Científicas, 2000.

Ladero Quesada, Miguel Ángel. Guzmán. La casa ducal de Medina Sidonia en Sevilla y su reino. 1282-1521. Madrid: Dykinson, 2015.

López Gómez, Óscar. La sociedad amenazada. Crimen, delincuencia y poder en Toledo a finales del siglo XV. Toledo: Ayuntamiento de Toledo, 2007.

Merino Álvarez, Abelardo. La sociedad abulense durante el siglo XVI: la nobleza. Discursos leidos ante la Real Academia de la Historia en la recepción pública del señor don Abelardo Merino Álvarez. Madrid: Imprenta del Patronato de Huérfanos de los Cuerpos de Intendencia e Intervención Militares, 1926.

Monsalvo Antón, José M. ${ }^{\mathrm{a}}$. «El realengo y sus estructuras de poder durante la Baja Edad Media». En Ser Quijano, Gregorio del (coord.). Historia de Avila. III. Edad Media (Siglos XIV-XV). Ávila: Institución Gran Duque de Alba, 2006, pp. 71-176.

Monsalvo Antón, José M. a . «Ideario sociopolítico y valores estamentales de los pecheros abulenses y salmantinos (ss. XIII-XV)». Hispania, vol. 238, 2011, pp. 325-362.

Monsalvo Antón, José M. ${ }^{a}$. "Las luchas de bandos en Ciudad Rodrigo durante la época Trastámara». En VAl VAldivieso, M. a Isabel del y Martínez Sopena, Pascual (dirs.). Castilla y el mundo feudal. Homenaje al profesor Julio Valdeón. Valladolid: Junta de Castilla y LeónUniversidad de Valladolid, 2009, vol. III, pp. 201-214.

Monsalvo Antón, José M. ${ }^{\mathrm{a}}$. "Torres, tierras, linajes: Mentalidad social de los caballeros urbanos y de la elite dirigentes en la Salamanca medieval (Siglos XIII-Xv)». En Monsalvo Antón, José

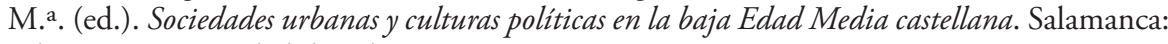
Ediciones Universidad de Salamanca, 2013, pp. 165-230.

Monsalvo Antón, José M. ${ }^{\mathrm{a}}$. "Violence between factions in medieval Salamanca. Some problems of interpretation». Imago Temporis. Medium Aevum, 2009, vol. 3, pp. 139-170. 
MÁXIMO DIAGO HERNANDO

Moreno Núñez, José Ignacio. Ávila y su Tierra en la Baja Edad Media (Siglos XIII-XV). Valladolid: Junta de Castilla y León, 1992.

Quintanilla Raso, M. ${ }^{a}$ Concepción. «Política ciudadana y jerarquización del poder. Bandos y parcialidades en Cuenca». En la España Medieval, 1997, vol. 20, pp. 219-250.

Rodríguez Molina, José. «Bandos en las ciudades del Alto Guadalquivir (Siglos XV-Xvi). Repercusiones». En Las ciudades andaluzas (siglos XIII-XVI). Actas del VI Coloquio Internacional de Historia Medieval de Andalucía. Málaga: Universidad de Málaga, 1991, pp. 37-50.

Rodríguez Villa, Antonio. Un cedulario del Rey Católico (1508-1509). Madrid: s.n., 1909.

Ruiz Ayúcar, M. a José. "Aportación a la historia de las Comunidades en Ávila». Cuadernos Abulenses, 1987, vol. 7, pp. 219-240.

Sánchez GiL, Julio. «Fernán Gómez Dávila, un miembro de la casa de Navamorcuende al servicio de la nueva milicia castellana». Cuadernos Abulenses, 2006, vol. 35, pp. 281-308.

Santa Cruz, Alonso de. Crónica del emperador Carlos V. 5 vols. Madrid: Real Academia de la Historia, 1920-1925.

Santos Burgaleta, Manuel. "Extensiones de poder”: Una propuesta de análisis en torno a la articulación de los espacios de poder. La valía del doctor Talavera en Salamanca (1475-1521)». En Bravo Lozano, Jesús. (ed.). Espacios de poder: Cortes, ciudades y villas (S. XVI-XVIII). Madrid: J. Bravo, 2002, vol. II, pp. 73-92.

Santos Burgaleta, Manuel. «Poderes urbanos y Comunidades de Castilla: La Junta de Salamanca a través de sus actas de sesiones (agosto de 1520-abril de 1521)». Salamanca. Revista de Estudios, 2002, vol. 48, pp. 357-441.

Sobrino Chomón, Tomás. «El monasterio premonstratense de Sancti Spiritus». Cuadernos Abulenses, 1993, vol. 19, pp. 11-39.

Tapia SÁnchez, Serafín de. «Ávila en la encrucijada de Castilla: La rebelión de las Comunidades». En Martín García, Gonzalo (coord.) Historia de Ávila. V. Edad Moderna (Siglos XVI-XVIII. 1. ${ }^{a}$ Parte). Ávila: Institución Gran Duque de Alba, 2013, pp. 145-235.

Tapia SÁnchez, Serafín de. «La participación de Ávila en las Comunidades de Castilla». En Ávila en el tiempo. Homenaje al profesor Ángel Barrios. Ávila: Diputación de Ávila, 2007, vol. III, pp. 139-182.

Zurita, Jerónimo. Historia del rey don Hernando el Católico: De las empresas y ligas de Italia (ed. de Ángel Canellas). 6 vols. Zaragoza: Gobierno de Aragón, 1989-1996. 